Boise State University

ScholarWorks

Mathematics Faculty Publications and

Presentations

Department of Mathematics

$11-2008$

\title{
Prey Behavior, Age-Dependent Vulnerability, and Predation Rates
}

Susan Lingle

University of Alberta

Alex Feldman

Boise State University

Mark S. Boyce

University of Alberta

W. Finbarr Wilson

McIntyre Ranch Coyote and Deer Project 


\title{
Prey Behavior, Age-Dependent Vulnerability, and Predation Rates
}

\author{
Susan Lingle, ${ }^{1,2,3, *}$ Alex Feldman, ${ }^{4, \dagger}$ Mark S. Boyce, ${ }^{3, \star}$ and W. Finbarr Wilson ${ }^{1, \S}$
}

1. McIntyre Ranch Coyote and Deer Project, Box 914, Magrath, Alberta T0K 1J0, Canada;

2. Department of Neuroscience, University of Lethbridge, Lethbridge, Alberta T1K 3M4, Canada;

3. Department of Biological Sciences, University of Alberta, Edmonton, Alberta T6G 2E9, Canada;

4. Department of Mathematics, Boise State University, Boise, Idaho 83725

Submitted July 15, 2007; Accepted June 10, 2008;

Electronically published October 7, 2008

Online enhancements: appendixes.

ABSTRACT: Variation in the temporal pattern of vulnerability can provide important insights into predator-prey relationships and the evolution of antipredator behavior. We illustrate these points with a system that has coyotes (Canis latrans) as a predator and two species of congeneric deer (Odocoileus spp.) as prey. The deer employ different antipredator tactics (aggressive defense vs. flight) that result in contrasting patterns of age-dependent vulnerability in their probability of being captured when encountered by coyotes. We use longterm survival data and a simple mathematical model to show that (1) species differences in age-dependent vulnerability are reflected in seasonal predation rates and (2) seasonal variation in prey vulnerability and predator hunt activity, which can be associated with the availability of alternative prey, interact to shape seasonal and annual predation rates for each prey species. Shifting hunt activity from summer to winter, or vice versa, alleviated annual mortality on one species and focused it on the other. Our results indicate that seasonal variation in prey vulnerability and hunt activity interact to influence the impact that a predator has on any particular type of prey. Fur-

* Corresponding author. Address for correspondence: Department of Biology, University of Winnipeg, Winnipeg, Manitoba R3B 2E9, Canada; e-mail: s.lingle@uwinnipeg.ca.

† E-mail: alex@math.boisestate.edu.

‡ E-mail: boyce@ualberta.ca.

§ E-mail: finbarr2@yahoo.com.

Am. Nat. 2008. Vol. 172, pp. 712-725. (c) 2008 by The University of Chicago. 0003-0147/2008/17205-42726\$15.00. All rights reserved.

DOI: $10.1086 / 591675$ thermore, these results indicate that seasonal variation in predation pressure is an important selection pressure shaping prey defenses.

Keywords: age-dependent vulnerability, alternative prey, antipredator behavior, predator-prey, seasonality, temporal variation.

For many species, vulnerability to predation is a simple inverse function of age; however, this is not always the case. Some animals become exposed to predators only after they mature (Lloyd and Dybas 1966). Others move in and out of vulnerable periods as they seasonally change habitats (Nicholson et al. 1997) or devote attention to activities that distract them from predators (Molinari-Jobin et al. 2004; Hoogland et al. 2006). Variation in the temporal pattern of vulnerability can provide important insights into the evolution of prey behavior and the ecology of predator-prey relationships (Hastings 1983; Abrams and Walters 1996).

An animal's lifestyle or antipredator tactics can affect its vulnerability to predators at a certain age or time of year. The result is that species employing certain behaviors will tend to show characteristic temporal patterns of agedependent vulnerability (fig. 1). For example, a young caribou (Rangifer tarandus) or wildebeest (Connochaetes taurinus), which follows its mother within a few hours of birth, will have an elevated probability of being encountered compared with a young Thomson's gazelle (Gazella thomsoni) or deer (Odocoileus spp.), which spends most of its time in hiding (Ralls et al. 1986). The probability of being encountered will rise steeply for the hiding animal when it abandons the hiding tactic (FitzGibbon 1990). The probability of being encountered will not necessarily change for the following animal as it ages unless the animal occupies enemy-free refuges that it abandons as it matures (Bergerud et al. 1984; Festa-Bianchet 1988). In contrast to these two patterns, a young rodent that remains belowground until it reaches a certain age and then hibernates a few months later may have an elevated probability of being encountered by terrestrial predators during the time of year it lives aboveground and a low encounter probability when it lives belowground (fig. 1a). 

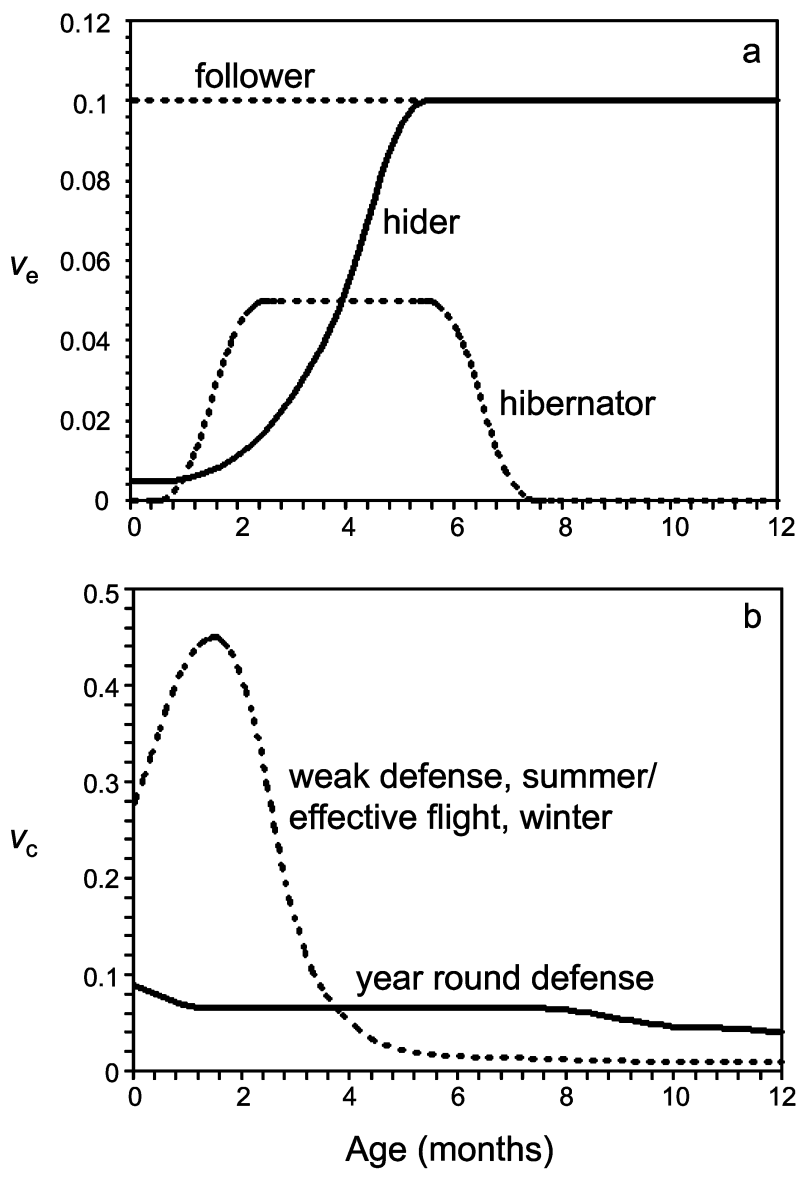

Figure 1: Age-dependent vulnerability patterns associated with variation in prey lifestyle or antipredator tactics. $a$, Probability that an animal is encountered per unit hunt time, $v_{\mathrm{e}}$, during the first year of life for a neonatal ungulate having a hider or follower lifestyle or for a hibernating rodent. $b$, Probability that an animal is captured when encountered, $v_{c}$, during the first year of life depending on its ability to employ tactics of aggressive defense or flight. The plotted values are hypothetical, although the line representing the hider (in $a$ ) is based on data collected for whitetailed deer fawns and mule deer fawns, the line reflecting weak defense in summer and flight in winter (in $b$ ) is based on data for white-tailed deer, and the line representing year-round aggressive defense (in $b$ ) is based on data for mule deer (fig. 2). How temporal variation in vulnerability translates to mortality depends on the level of hunt activity found at different times of year.

Prey defenses also affect the probability of an animal being captured following an encounter. Aggressive defense by adults can be invaluable in reducing a young animal's susceptibility to being captured (Montgomerie and Weatherhead 1988; Cocroft 2002; Lingle et al. 2005). Attempts to flee may be futile for immature animals, but they will become more effective when the young animal attains the physical attributes needed to outdistance a predator (FitzGibbon 1990). However, not all species are equally capable of employing the tactics of aggressive defense or flight (Dyrcz et al. 1981; Burger 1984; Lingle et al. 2005). Variation in their abilities to employ certain defenses may give rise to characteristic patterns of age-dependent vulnerability, in this case involving the probability of capture per encounter (fig. 1b).

Neonatal white-tailed deer (Odocoileus virginianus) fawns fit the pattern that can be considered to be stereotypical of ungulates and many other species (fig. 1b). They are highly susceptible to being captured when encountered by coyotes (Canis latrans) early in life (Lingle et al. 2005); during this period, they spend the majority of their time in hiding. When a white-tailed deer fawn reaches approximately 4-5 months of age, it can gallop fast enough to outdistance coyotes in most situations and its susceptibility to being captured declines steeply (Lingle and Pellis 2002).

Although mule deer (Odocoileus hemionus) fawns are also hiders, active defense by females greatly reduces the probability that a mule deer fawn will be captured when encountered by predators during the initial months of life, compared with a white-tailed deer fawn (Lingle et al. 2005; fig. 1b). However, a mule deer's probability of being captured does not drop significantly as it matures, because mule deer use a jumping gait, the stot, that does not enable fawns of any age to outdistance coyotes (Lingle and Pellis 2002). Instead of fleeing from predators, mule deer fawns continue to rely on defense provided by adult females throughout the first year of life. Consequently, even though white-tailed deer fawns are more likely to be captured early in life, mule deer fawns are more likely to be captured when encountered by coyotes by the time fawns are 5 months old (fig. 1b). These species' differences in behavior and vulnerability exist even though white-tailed deer and mule deer are similar in size (Mackie 1964; Whittaker and Lindzey 1999), productivity (Beasom and Wiggers 1986; Whittaker and Lindzey 2001), and feeding habits (Anthony and Smith 1977; Krausman 1978).

To understand mechanisms influencing predation rates, it is necessary to consider how a prey animal's vulnerability varies with its age and over time, because overall predation rates for a given season, year, or geographic region are a cumulative function of instantaneous predation risk. However, prey vulnerability is not the only source of temporal variation that affects predation rates. The size and hunting tactics of a predator can affect the size or age of prey it captures (Paquet 1992; Pierce et al. 2000; Downes 2002; Essington and Hansson 2004), and seasonal variation in alternative prey can affect the time of year when a predator hunts any particular species (Patterson et al. 1998; Cooper et al. 1999; Ackerman 2002; Miller et al. 2006). A prey species will presumably suffer the greatest impact from predators that target the animal at the time of year when it is most vulnerable. 
In this article, we use the coyote-deer system to examine two hypotheses: (1) age-dependent changes in vulnerability influence predator foraging behavior and lead to seasonal differences in predation rates on white-tailed deer and mule deer fawns, and (2) seasonal variation in vulnerability and hunt activity interact to result in different cumulative outcomes for seasonal and annual mortality. We used long-term survival data to test whether whitetailed deer fawns were more likely than mule deer fawns to succumb to predation during summer, when individuals are less than 12 weeks of age, and whether mule deer fawns were more likely to die during winter, when they are approximately 20-40 weeks of age, as is expected if agedependent variation in prey vulnerability influences coyote foraging behavior (Lingle and Pellis 2002; Lingle et al. 2005). We then developed a mathematical model to examine how seasonal changes in prey vulnerability and hunt activity would be expected to interact to shape cumulative seasonal and annual predation rates for the two species of deer. We focused on temporal variation in vulnerability during an animal's first year of life because of the nature of our data, but it would be equally valid to ask how vulnerability varies across seasons for older animals.

\section{Methods}

Research was conducted between 1994 and 2007 on a 225$\mathrm{km}^{2}$ cattle ranch in southern Alberta, Canada $\left(49^{\circ} \mathrm{N}\right.$, $\left.112^{\circ} \mathrm{W}\right)$. The ranch is an open, rolling landscape dominated by fescue grassland (Festuca scabrella), with patches of short shrubs (0.5-2 m tall) in more mesic areas. The majority of white-tailed deer and mule deer females raised their fawns along three slope systems formed by a prominent escarpment and two deep river valleys. Most mule deer females remained near these slopes throughout winter, and most white-tailed deer moved to gently rolling terrain by late September. Nevertheless, there was considerable spatial overlap between the species in winter, as well as in summer (see Lingle [2000] for details and a map). Overall, deer density declined during the study, especially for mule deer. There were approximately 12 white-tailed deer and seven mule deer per square kilometer in a central $20-\mathrm{km}^{2}$ study area (hereafter referred to as the central study area) during the winters of 1994-1995 and 1995-1996 (Lingle 2000) and nine white-tailed deer and two mule deer per square kilometer in the winter of 2006-2007 (S. Lingle, unpublished data). Densities of white-tailed deer in the central study area were considerably lower during summer (fig. B1 in the online edition of the American Naturalist). Hunting of deer or coyotes by humans was not permitted inside the ranch. A barbed wire fence prevented cattle, but not other animals, from moving in and out of the ranch.

\section{Survival of Marked Fawns}

Fawns were caught in a $20-\mathrm{km}^{2}$ portion of the ranch, the central study area, in 1994 and 1995; this area was extended to a total of $50 \mathrm{~km}^{2}$ from 2000 to 2004 and to a total of $60 \mathrm{~km}^{2}$ in 2005 (hereafter referred to as the extended study area). Fawns were captured and ear tagged during their first week of life and were subsequently identified by the color of these tags (see Lingle 2000, 2003 for details; University of Lethbridge Canadian Council on Animal Care protocols 0002, 0210, and 0560). Fawns were assigned a week of birth (birth date) on the basis of the animal's apparent age when captured, using mobility, size, eye color, and the condition of the umbilicus as a guide (Haugen and Speake 1959). In 7 years (1994, 1995, 2000, 2001, 2003-2005), fawns were monitored by visual sighting using binoculars and spotting scopes. In four of these years (2000, 2001, 2004, 2005), we also used radio transmitters with 12-h mortality signals to facilitate tracking during the first few months, when fawns spend most of their time bedded. Altogether, 131 white-tailed deer fawns from 125 mothers and 210 mule deer fawns from 177 mothers were tagged, with 72 of the white-tailed deer and 83 of the mule deer fawns having radio transmitters (see table A1 in the online edition of the American Naturalist for a breakdown by year).

In 2000, we glued 10-g transmitters directly to the fur on each fawn's back, and in 2001 we attached the same transmitters to an expandable plastic collar designed to fall off when the fawn was approximately 6 months of age. In most cases, these transmitters fell off within 6 weeks. In 2004 and 2005, we attached a smaller transmitter to an ear tag $(4 \times 2 \mathrm{~cm} ; 9.5 \mathrm{~g}$, including transmitter $)$, and these functioned successfully throughout the transmitter's 4month life span. We attempted to obtain a signal every day from fawns with transmitters, and we performed a thorough search for each missing fawn typically every third day. The disappearance of a fawn, including fawns with transmitters and those carrying only ear tags, was attributed to a particular week. If the exact date of a fawn's disappearance or death was not known, we used the middate between the time the fawn was last seen and the first thorough attempt to locate it without success (several attempts were made before concluding that a fawn had disappeared).

Fawns that were apparently healthy and then suddenly disappeared (with no evidence of dispersal activity from the area) were presumed to have died from coyote predation, as were fawns for which the predation event was observed or confirmed by evidence associated with a carcass. Undoubtedly, some of these fawns died from causes other than predation; however, predation appeared to have been the dominant cause of mortality for fawns in summer 
and winter (Lingle 2000; app. A in the online edition of the American Naturalist). Fawns known to have died from a cause other than predation (e.g., health, road kill, or shot when traveling outside ranch) or to have moved far outside the ranch before winter were excluded from survival analyses as of the season that they disappeared, including two white-tailed deer and two mule deer from summer and seven white-tailed deer and one mule deer from winter. Thirty-five fawns that disappeared within a few weeks of capture had not been adequately monitored for us to be confident about the causes of death. To ensure that uncertainty about these fawns did not bias results one way or the other, they were included in one statistical analysis and excluded from another.

We used a logistic regression model (Stata 10.0, logit procedure) to test each of two predictions associated with the hypothesis that age-dependent changes in vulnerability lead to seasonal differences in predation rates for the two deer species: $\left(\mathrm{P}_{1}\right)$ white-tailed deer fawns were more likely to die when $\leq 12$ weeks of age, and $\left(\mathrm{P}_{2}\right)$ mule deer fawns were more likely to die when $20-40$ weeks of age. The age groups identified for these analyses were selected on the basis of observations of coyotes hunting deer that suggested that white-tailed deer fawns were more vulnerable when $\leq 12$ weeks of age (Lingle et al. 2005) and that mule deer were more vulnerable when they were between 20 and 40 weeks of age (Lingle and Pellis 2002; fig. 2). We did not have sufficient data for fawns older than 40 weeks of age to assess behavioral vulnerability (which was based on observations of coyote hunting deer) or survival (which was based on monitoring marked individuals) beyond that age.

In addition to species, which was the main independent variable of interest, we included year, sex, birth date (which was tested as a continuous factor and also as a categorical factor distinguished into early, average, or late birth date), and the portion of the study area in which the fawn lived (with the study area partitioned into four units) as covariates, and we followed a stepwise backward procedure, eliminating terms when $\alpha>0.10$. We were unable to include body mass at birth in the survival analyses because we could not assign an exact day of birth to individual fawns that were captured, which is required to assess how body mass changes with age. However, we used a generalized estimating equation (Stata 10.0, xtgee), with species and year as independent variables and the mother's identity as a grouping variable, to compare the mass of 31 white-tailed deer and mule deer fawns from 18 mothers that were known to be $<6 \mathrm{~h}$ old when captured.

\section{Fawn: Doe Ratios Obtained from Census Data}

In 10 winters (1994-1995 through 2006-2007, excluding 1996-1997 and 1997-1998), we conducted censuses of
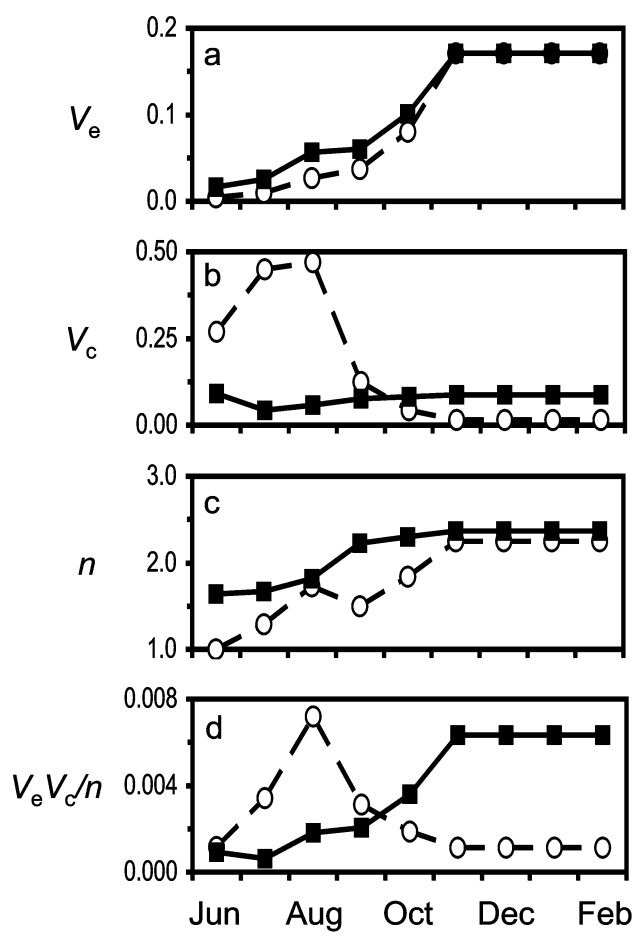

Figure 2: Values used to model kill rates and resulting survival patterns for mule deer fawns (solid lines, squares) and white-tailed deer fawns (dashed lines, circles). a, Probability that an individual fawn is encountered per hour of hunt time or encounter efficiency, $v_{\mathrm{e}}$. $b$, Probability a fawn is captured per encounter or capture success, $v_{c}$. $c$, Number of fawns present per encounter, $n$. $d$, Overall vulnerability, $v_{\mathrm{e}} v_{\mathrm{c}} / n$ (see table $\mathrm{C} 1$ in the online edition of the American Naturalist for values). Data are based on observations of coyotes hunting fawns (Lingle and Pellis 2002; Lingle et al. 2005).

deer in the central study area to track changes in the ratio of juveniles to adult females (fawn : doe ratio) in the population, for use as an index of fawn survival during winter. The census data were used in addition to data on marked fawns because they captured a larger sample of the fawn population. A person walked an established route and stopped at predetermined vantage points to search for and identify deer in the area (Lingle 2000). Each vantage point had been selected to view a certain portion of the study area that, when combined, covered the entire census area. The height of land from which we searched for deer, the absence of trees, and the desiccated condition of vegetation from October through March made it possible to spot the vast majority of deer in the central study area for which results are presented. The observer moved and spotted deer in one direction (traveling in the opposite direction on alternate censuses) and followed guidelines related to animal movement to avoid double- or undercounting deer.

Two to three censuses were conducted in autumn (Oc- 
tober 15-November 5), during midwinter (December 20January 20), and in late winter (March 1-20), with additional sampling from October through March when personnel availability permitted (1994, 2000, and 2001). We averaged values for fawn : doe ratios from censuses conducted during the same time period. Fawn: doe ratios obtained within 1 week of each other rarely differed by more than 0.1 ; if they did, we conducted additional censuses. Data obtained from censuses were also used to estimate the abundance of fawns and females in winter and in summer (see app. B in the online edition of the American Naturalist for methods and results related to deer abundance).

We focused on animals living in the central study area when using data on marked fawns and fawn: doe ratios to illustrate survival of fawns in summer or winter, respectively. This is because we had monitored fawns in that area since 1994, the two species had the greatest overlap in this area in both summer and winter, and large annual changes in the numbers of white-tailed deer and mule deer in this area enabled us to consider mortality patterns across years in which the absolute and relative abundance of the two species differed considerably.

\section{The Model}

We prepared a model to examine how age-dependent variation in an animal's vulnerability to capture, $v(t)$, affected seasonal and annual predation rates, using data on the probability of a fawn being encountered or captured that were collected by observing coyotes hunting deer (Lingle and Pellis 2002; Lingle et al. 2005). To calculate the number of fawns killed by coyotes per day, we multiplied three general terms: (i) hunt time, hours per day spent hunting fawns; (ii) encounter rate, the number of fawns encountered per hour of hunt time; and (iii) capture success, the probability that a fawn is captured per encounter. A fawn's vulnerability was represented in the model by the probability that a fawn was encountered per hour of hunt time, encounter efficiency $\left(v_{\mathrm{e}}\right)$, and the probability that a fawn was captured when encountered, capture success $\left(v_{c}\right)$. The model we developed calculates kill rates for each species independently.

Time Periods. Most fawns from both species are born during a 3-week interval in June. In this model, we assumed all fawns were born on a median birth date of June 12 $(t=0)$, and we tracked their survival to the end of February of the following year $(t=261)$. The probability of a fawn being encountered or captured varies continuously throughout the year (e.g., fig. 1). However, we did not have sufficiently fine-grained data to produce continuous functions for these parameters and instead used constant values for different time periods (fig. 2; table $\mathrm{C} 1$ in the online edition of the American Naturalist). We partitioned data on encounter efficiency and capture success into four monthly periods during summer (June through September) and into one time period for winter (November 1February 28). It seemed important to make finer time distinctions for summer because of the rapid development of fawns in that season. Because no data were collected for October, we interpolated September and winter data points for that month.

Hunt Time. Seasonal and annual variation in the time predators devote to hunting a particular prey species might arise in response to a few factors, including variation in the availability of alternative prey (Lingle 2000; Miller et al. 2006). We plotted three scenarios showing seasonal variation in the time one coyote pack spends hunting deer per day $\left(t_{h}\right.$, expressed as hunt $h$ day $\left.^{-1}\right)$ : (1) coyotes spend more time hunting deer in summer $\left(1.0 \mathrm{~h} \mathrm{day}^{-1}\right)$ than in winter $\left(0.25 \mathrm{~h} \mathrm{day}^{-1}\right)$, (2) coyotes spend equal time hunting deer in summer and in winter $\left(0.5 \mathrm{~h} \mathrm{day}^{-1}\right)$, and (3) coyotes spend more time hunting deer in winter $(1.0 \mathrm{~h}$ day $\left.^{-1}\right)$ than in summer $\left(0.25 \mathrm{~h} \mathrm{day}^{-1}\right)$. Although the numerical values are hypothetical, they are consistent with observations revealing that a hunt typically lasts $0.5-1.0 \mathrm{~h}$ (Lingle 2000). Coyote packs were only occasionally observed embarking on more than one hunt per day and were frequently observed not initiating a hunt for full days (observations were limited to daylight hours). Hunt time included time coyotes spent searching for and attacking deer. Attack time comprised a small portion of the hunt time $(<0.5 \%$ for June and July and $<2 \%$ for August and September for both deer species; $<1 \%$ for white-tailed deer and $5 \%$ for mule deer during winter) and did not prevent coyotes from making further encounters. The time each pack spent hunting deer per day was multiplied by the number of coyote packs, $p$, to represent total hunt time, $p t_{\mathrm{h}}$. In our model, we fixed $p$ at a value of 4 because four coyote packs had dens within the central study area during summer and had rendezvous sites during winter (Lingle 2000).

Encounter Rate. Our main interest in building this model was to investigate the influence of a fawn's vulnerability to capture, following an encounter, on kill and survival rates. We wanted a probability of a fawn being encountered that reflected temporal and interspecific variation in deer behavior, which was mostly associated with variation in the hiding behavior of fawns. A fawn was defined as being encountered when coyotes within $200 \mathrm{~m}$ of a fawn appeared to detect it (Lingle and Pellis 2002; Lingle et al. 2005). The probability that an individual fawn would be encountered per hour of hunt time, encounter efficiency 
$\left(v_{\mathrm{e}}\right)$, was calculated using data from years in which coyote hunts were observed continuously, including four summers $(1995,1999,2000,2001)$ and one winter (19951996). For each hunt or portion of a hunt that was observed, we identified the number of fawns encountered per hour of hunt time and expressed this as a proportion of the total number of fawns in the study area. Fawn abundance was estimated during winter using census data and during summer using data on marked fawns and census data (see app. B). We averaged the starting and ending abundance of fawns during each time period before calculating encounter efficiency for each time period. Given the small number of observed encounters for each summer, it seemed more appropriate to obtain one mean value for encounter efficiency from data collected in all summers than to average mean values obtained from each summer. We do not consider the absolute values for encounter efficiency to be reliable because of the low rate at which coyotes encountered fawns in summer and because we had only 1 year of data for winter. However, the values should capture age-dependent and interspecific variation in encounter efficiency (fig. 2), which was the main reason to include this parameter in the model.

The number of fawns alive at any time (starting abundance of fawns, $N$, minus number of fawns killed to date, $K$ ) was multiplied by the encounter efficiency to calculate the encounter rate, that is, the number of encounters with fawns per hour of hunt time:

no. fawns encountered $h^{-1}$ hunt time

$$
=(N-K)\left(v_{\mathrm{e}}\right) \text {. }
$$

Both sides of equation (1) were divided by $N$ to represent encounter rate as the proportion of the initial fawn population encountered per hour, with $k$ representing the proportion of the population killed to date and $1-k$ representing the proportion surviving:

$$
\begin{aligned}
& \text { proportion of initial fawn population } \\
& \text { encountered } \mathrm{h}^{-1} \text { hunt time } \\
& =(1-k)\left(v_{\mathrm{e}}\right)
\end{aligned}
$$

Capture Success. The probability that a fawn is captured per encounter (capture success, $v_{c}$ ) was obtained from previously published results (Lingle and Pellis 2002; Lingle et al. 2005), although data were restricted to groups having fawns and partitioned into finer time intervals for summer (fig. 2). Even though coyotes commonly encounter more than one fawn at a time, only once (in a situation involving a pair of newborn twins) were they observed to capture more than a single fawn per encounter (Lingle et al. 2005). It was therefore necessary to adjust capture success for the number of fawns present per encounter, $n$, to calculate the probability of an individual fawn being captured when it was encountered, $v_{\mathrm{c}} / n$ (fig. 2).

Predicted Predation Rates and Survival. The total hunt time per day $p t_{\mathrm{h}}$, proportional encounter rate $(1-k) v_{\mathrm{e}}$, and capture success $v_{c} / n$, were multiplied together to determine the proportion of the initial fawn population captured per day:

$$
\begin{aligned}
& \text { proportion of initial fawn } \\
& \text { population captured day }{ }^{-1} \\
& \quad=\frac{p t_{\mathrm{h}}(1-k) v_{\mathrm{e}} v_{\mathrm{c}}}{n} .
\end{aligned}
$$

Equation (3) describes the proportion of fawns captured on one day for a given size of the fawn population. We were interested in the total proportion of the initial fawn population killed, $k$, from $t=0$ to different points in time. We therefore represented the rate of change of $k$ as a time derivative and solved the resulting differential equation (4) for $k$ :

$$
\frac{\mathrm{d} k}{\mathrm{~d} t}=\frac{p t_{\mathrm{h}}(1-k) v_{\mathrm{e}} v_{\mathrm{c}}}{n}
$$

In "Results" we show survival, $s=1-k$, as a function of time $s(t)$.

\section{Results \\ Species Differences in Seasonal Predation Rates}

White-tailed deer fawns were more likely than mule deer fawns to die during the first 12 weeks of life (tables 1, 2), which generally corresponded to June through midSeptember. Mule deer fawns were more likely than whitetailed deer fawns to die between 20 and 40 weeks of age (tables 1,3), which generally corresponded to November through March. The species difference in early mortality persisted beyond the first few weeks of life. Of fawns that survived to 4 weeks of age, $54 \%$ of white-tailed deer fawns and $84 \%$ of mule deer survived to 12 weeks. Considerable annual variation in fawn mortality occurred in summer and in winter (figs. 3, 4; tables 2, 3, A1).

An analysis of summer survival that included 35 fawns that disappeared during the first 3 weeks of life and for whom tracking was insufficient to confidently assign a cause to their disappearance produced the same results as an analysis that excluded these fawns (table 3). The fact 
that $69 \%$ of these fawns were white-tailed deer, even though white-tailed deer fawns comprised only $38 \%$ of the overall sample, suggested that most of this group had succumbed to predation. There is no reason to expect such a biased distribution if these fawns had died from ill health or an accident. White-tailed deer and mule deer fawns that were captured shortly after birth did not differ in weight (mean \pm SE body mass: mule deer, $3.68 \pm 0.06, n=$ 22; white-tailed deer, $3.68 \pm 0.15, n=9$; effect of species, $\beta \pm S E=0.07 \pm 0.18, z=0.40, P=.69$ ).

Data restricted to the central study area (figs. 3, 4) revealed that the seasonal differences in mortality persisted across years, despite large changes in the absolute and relative abundance of fawns of the two species (fig. B1). White-tailed deer fawns experienced higher levels of mortality from June through September in 7 years of study (fig. 3; table A1). The steeper decline in fawn : doe ratio from autumn through late winter for all years in which there were enough fawns of each species alive at the start of winter to enable comparison (1994, 1995, 1999, 2003, 2005, 2006, with the same trend in other years) indicated that mule deer fawns consistently experienced higher mortality during winter than white-tailed deer fawns (fig. 4).

Trends suggested by the age structure data were consistent with survival data for marked fawns. Fawn : doe ratios in autumn were low in years in which marked fawns had poor summer survival (e.g., figs. 3, 4, 2000, 2001, 2002) and high following summers in which marked fawns had good survival (e.g., 1994, 1995, 2003). An exception was 2004, when a large number of females of both species failed to produce fawns that summer (S. Lingle, personal observation). In winters in which the age structure data suggested a nearly total loss of fawns in the population (fig. 4, 1994, 1999, 2003 for mule deer), there was at most one surviving marked fawn in the central study area (fig. 4; table A1).

There was no indication that differential survival of adult females offered an alternative explanation for the steeper decline of mule deer fawn : doe ratios over winter. The number of females remained relatively stable for both species from autumn through late winter. There was no tendency for the number of white-tailed deer females to decline more steeply than the number of mule deer fe-
Table 2: Logistic regression used to test effect of species on survival of fawns during first 12 weeks of life, while controlling for other factors

\begin{tabular}{lrccc}
\hline Variable & $\beta$ & SE & $z$ & $P$ \\
\hline Intercept $^{\text {Species }}{ }^{\mathrm{a}}$ & .45 & .75 & -.60 & .55 \\
Year: $^{\mathrm{b}}$ & -1.86 & .30 & -6.14 & $<.001$ \\
1995 & & & & \\
2000 & -1.11 & .74 & -1.50 & .13 \\
2001 & -3.07 & .70 & -4.36 & $<.001$ \\
2003 & -3.03 & .70 & -4.32 & $<.001$ \\
2004 & -3.32 & .81 & -.74 & .46 \\
2005 & -3.09 & .74 & -4.27 & $<.001$ \\
Area: & & & & $<.001$ \\
East & 1.07 & .37 & 2.87 & .004 \\
Ranch & .49 & .65 & .76 & .45 \\
North & -.19 & .45 & -.42 & .67 \\
\hline
\end{tabular}

Note: Data are from 208 mule deer fawns from 175 mothers and 129 whitetailed deer fawns from 123 mothers. The effects of birth date $(\beta \pm \mathrm{SE}=$ $-0.16 \pm 0.20, z=-0.82, P=.41)$ and $\operatorname{sex}(\beta \pm \mathrm{SE}=-0.23 \pm 0.28$, $z=-0.80, P=.42$ ) were not significant. Species remained significant when only one twin was included in the analysis for cases in which we had captured maternal twins $(\beta \pm \mathrm{SE}=-2.02 \pm 0.33, z=6.09, P<.001)$ and when 35 fawns that disappeared early and were not monitored sufficiently to assign a cause of disappearance were excluded $(\beta \pm \mathrm{SE}=-1.73+0.34, z=5.07$, $P<.001)$.

${ }^{\mathrm{a}}$ Reference $=$ mule deer.

${ }^{\mathrm{b}}$ Reference $=1994$.

${ }^{\mathrm{c}}$ Reference $=$ central

males, as would be expected if greater mortality of whitetailed deer females accounted for the more gentle decline in fawn : doe ratios in that species (average change \pm SE in female numbers from autumn to late winter censuses: white-tailed deer, $1.04 \pm 0.09$; mule deer, $0.95 \pm 0.09$ ). Most changes in the number of females recorded during censuses conducted within one winter appeared to be the result of short-term movements by females in and out of the census area.

\section{The Interaction between Prey Vulnerability and Hunt Activity}

The model suggested that white-tailed deer fawns will experience high annual levels of mortality when coyote hunt

Table 1: Percentage of marked fawns surviving $(n)$ from capture to 12 weeks in age, from 20 to 40 weeks, and from capture to 40 weeks, of fawns that were alive at the start of the period

\begin{tabular}{lccc}
\hline Species & Capture to 12 weeks & 20-40 weeks & Capture to 40 weeks \\
\hline White-tailed deer & $34(129)$ & $73(26)$ & $28(123)$ \\
Mule deer & $74(208)$ & $41(121)$ & $24(207)$ \\
\hline
\end{tabular}

Note: See table A1 in the online edition of the American Naturalist for survival of fawns captured in different years. 
Table 3: Logistic regression used to test effect of species on survival of fawns from 20 to 40 weeks in age, while controlling for other factors

\begin{tabular}{lcccc}
\hline Variable & $\beta$ & SE & $z$ & $P$ \\
\hline Intercept $_{\text {Species }^{\mathrm{a}}}$ & 1.89 & 1.32 & 1.43 & .15 \\
Year: $^{\mathrm{b}}$ & 2.16 & .68 & 3.17 & .002 \\
1995 & & & & \\
2000 & 1.77 & .80 & 2.20 & .03 \\
2001 & 1.79 & .94 & 1.89 & .06 \\
2003 & 1.73 & 1.00 & 1.72 & .09 \\
2004 & -.12 & .93 & -.13 & .90 \\
2005 & 2.86 & 1.19 & 2.40 & .02 \\
Area: & 2.77 & 1.06 & 2.60 & .009 \\
East & & & & \\
Ranch & .99 & .75 & 1.32 & .19 \\
North & .38 & .94 & 2.53 & .012 \\
\hline
\end{tabular}

Note: Data are from 121 mule deer fawns from 103 mothers and 26 whitetailed deer fawns from 25 mothers. The effects of birth date $(\beta \pm \mathrm{SE}=-$ $0.034 \pm 0.20, z=-0.12, P=.91)$ and $\operatorname{sex}(\beta \pm \mathrm{SE}=0.33 \pm 0.43, z=$ $0.76, P=.45)$ were not significant. Species remained significant when only one twin was included in the analysis for cases in which we had captured maternal twins $(\beta \pm \mathrm{SE}=2.12 \pm 0.70, z=3.05, P=.002)$.

${ }^{\mathrm{a}}$ Reference $=$ mule deer.

${ }^{\mathrm{b}}$ Reference $=1994$.

${ }^{\mathrm{c}}$ Reference $=$ central.

activity is weighted toward the summer months (figs. $5 a$, $\mathrm{C} 1 a$ in the online edition of the American Naturalist) and that mule deer fawns will experience high annual mortality when hunt activity is weighted toward the winter months (figs. $5 c, \mathrm{C} 1 c$ ). Simply by shifting hunt activity from summer to winter, white-tailed deer survival increased from 0.13 to 0.32 annually (i.e., June through $\mathrm{March}$ ) in our simulation (fig. 5). With the same seasonal shift in hunt activity, survival of mule deer fawns decreased from 0.20 to 0.03 annually.

Annual predation patterns revealed by the survival data were consistent with the results of the model. White-tailed deer fawns experienced the highest levels of annual mortality in years in which they experienced especially high levels of mortality during summer (fig. 4; 2000-2002). In contrast, mule deer experienced the highest levels of annual mortality in years in which they experienced heavy mortality during winter (fig. 4; 1994, 1999, 2003).

\section{Discussion}

In this study, we considered how temporal variation in vulnerability, which can be associated with variation in prey behavior, influenced seasonal and annual predation rates in a system having two species of deer as prey and coyotes as a predator. The consistency between the longterm survival data and the results of the model indicates that it is important to consider age-dependent (and other

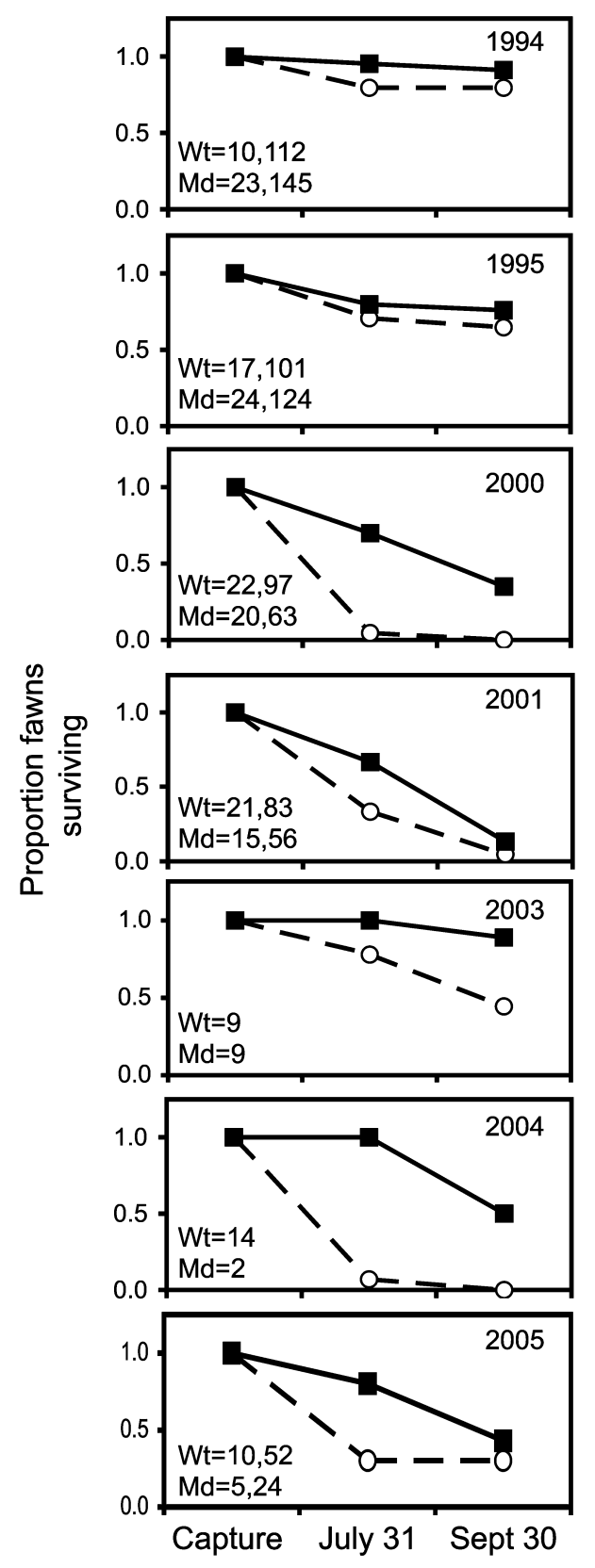

Figure 3: Proportion of marked mule deer fawns (solid lines, squares) and white-tailed deer fawns (dashed lines, circles) surviving from June, the time they were captured in the central study area, until the end of September. The number of marked fawns is listed in each plot, followed by an estimate of overall fawn abundance for summers in which it was available (fig. B1 in the online edition of the American Naturalist). We include data for years in which there was a very small sample of marked mule deer fawns in the central study area (2003-2005), reflecting the small number of mule deer fawns in this area, to illustrate that the species bias in mortality persisted regardless of large shifts in the relative and absolute abundance of fawns of the two species. See table A1 in the online edition of the American Naturalist for mortality rates of fawns in the extended study area. 

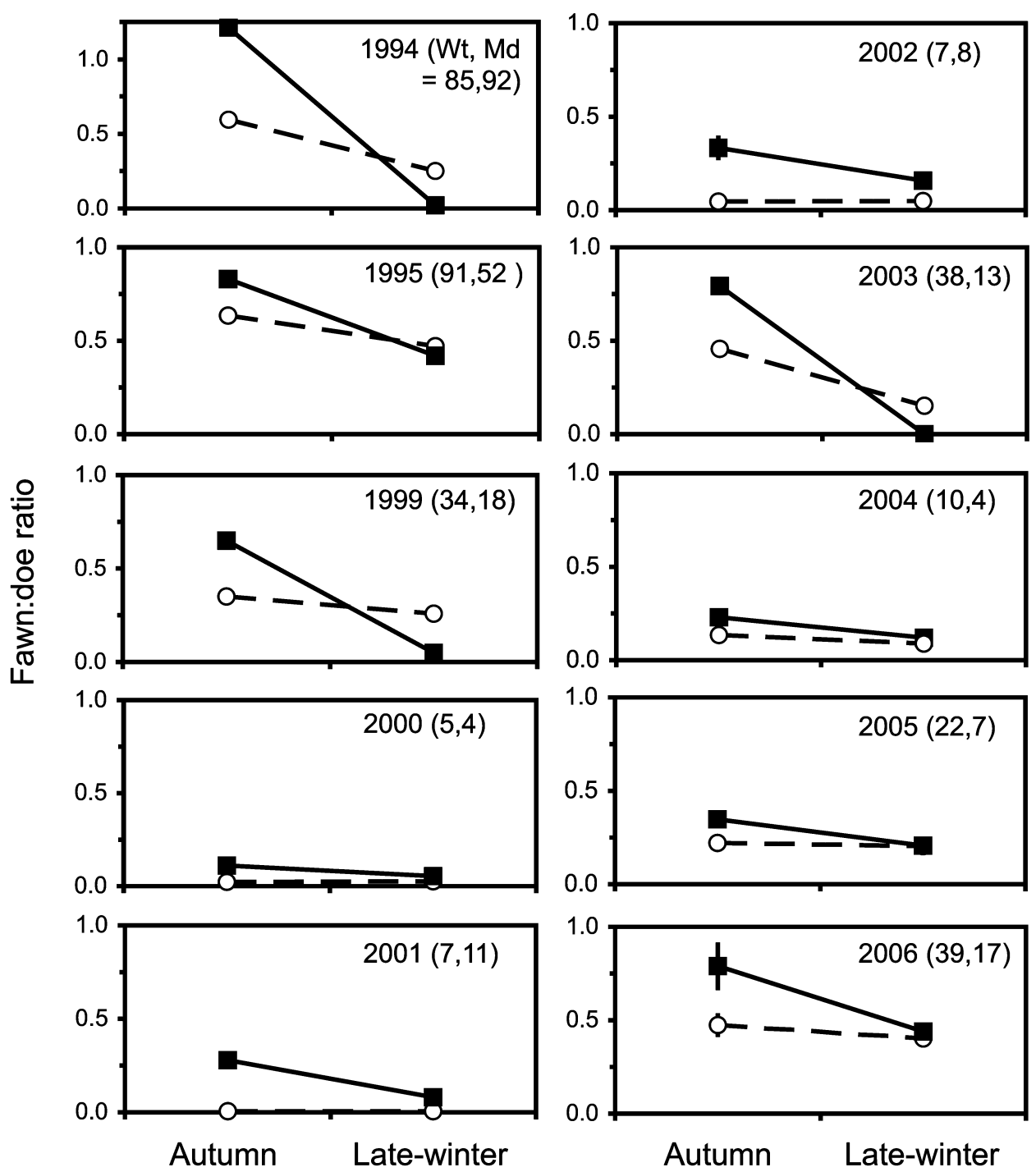

Figure 4: Mean $( \pm \mathrm{SE})$ ratio of fawns to females (fawn : doe ratio) in autumn (October-November) and late winter (February-March) in the central study area in different years for mule deer (solid lines, squares) and white-tailed deer (dashed lines, circles). Standard error values were usually too small to extend visibly beyond the data point. An estimate of the abundance of fawns during autumn is listed in each plot (see app. B in the online edition of the American Naturalist). For years in which there were enough fawns of the two species at the start of winter to permit comparison $(1994,1995,1999,2003,2005,2006)$, the steeper decline in fawn : doe ratio for mule deer indicates higher mortality of mule deer fawns than whitetailed deer fawns during winter. Number of white-tailed deer censuses used for autumn and late winter values, respectively: 1994, 5, 3; 1995, 3, 1; $1999,1,1 ; 2000,5,3 ; 2001,4,3 ; 2002,2,2 ; 2003,2,2 ; 2004,2,2 ; 2005,2,4 ; 2006,2$, 3. Number of mule deer censuses used for autumn and late winter values, respectively: 1994, 5, 3; 1995, 3, 1; 1999, 1, 1; 2000, 3, 2; 2001, 3, 2; 2002, 2, 2; 2003, 2, 2; 2004, 2, 2; 2005, 2, 4; 2006, 5, 4. The last census of 1995 was conducted on February 1, which meant that the fawn : doe ratio for late winter would have been overestimated (it was a shorter season, so there was less time for mortality) compared with other years. A large proportion of females of both species appeared to fail to produce fawns in summer of 2004, which contributed to the low fawn : doe ratios in autumn of that year.

temporal) changes in prey vulnerability to understand predator foraging behavior and resulting patterns of prey survival. We discuss these results, their implications for understanding predator-prey relationships, and their implications for understanding the evolution of prey defenses.

\section{Prey Vulnerability, Hunt Activity, and Predation Rates}

Our results supported hypothesis 1, that age-dependent changes in vulnerability lead to seasonal differences in predation on white-tailed deer and mule deer fawns. Although several factors (parasites, physical condition, productivity) 

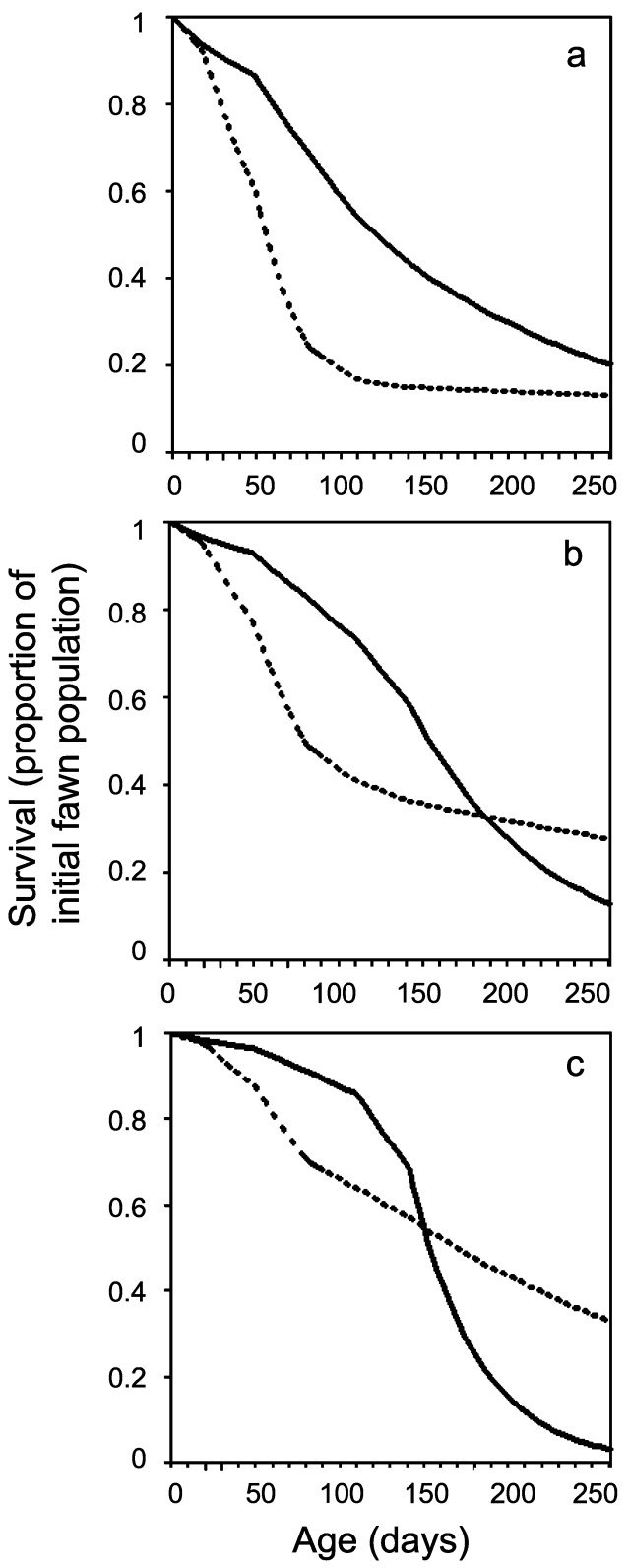

Figure 5: Survival (proportion of initial fawn population) for mule deer fawns (solid lines) and white-tailed deer fawns (dotted lines) predicted by the model when $(a)$ hunt time in summer exceeds hunt time during winter (1.0 and $0.25 \mathrm{~h} \mathrm{day}^{-1}$, respectively), (b) hunt time is similar in summer and in winter $\left(0.5 \mathrm{~h} \mathrm{day}^{-1}\right.$ for both), and $(c)$ hunt time in summer is less than hunt time during winter $\left(0.25\right.$ and $1.0 \mathrm{~h} \mathrm{day}^{-1}$, respectively). See appendix C in the online edition of the American Naturalist for kill rates producing these survival patterns.

could potentially explain a species difference in mortality within one season, we can think of no explanation other than the one proposed here (i.e., temporal variation in vulnerability) to account for the consistent preference of coyotes for white-tailed deer fawns in summer and mule deer fawns in winter. More detailed analyses have revealed that the species differences in vulnerability persist even after controlling for habitat variation, including the ruggedness of terrain and the density of vegetation (Lingle 2002; Lingle and Pellis 2002; Lingle et al. 2005). Whittaker and Lindzey (1999) suggested that mule deer fawns had better survival than white-tailed deer fawns in early summer at a study site in Colorado as a result of predator swamping; at that location, mule deer fawns were born, on average, several days later than white-tailed deer fawns and were also more abundant. Our data do not support this hypothesis. In contrast to the Colorado study site, fawns born earlier at our study location were no more likely to die as expected by the predator swamping hypothesis, and mortality of white-tailed fawns remained above that of mule deer after the birthing season.

It is possible that the fawns' vulnerability to capture declined more from summer to winter than was apparent from the data we gathered by watching coyotes hunt deer; we cannot completely disentangle prey vulnerability from hunter motivation (Downes 2002; Quinn and Cresswell 2004). We suspect that coyotes were generally more motivated by hunger to attack and capture deer and to accept risk of injury in winter than in summer.

Age-dependent vulnerability patterns would not be expected to be identical for animals of a given species living in different habitats or environmental conditions. Because deep snow can hinder an ungulate's ability to flee (Messier and Barrette 1985; Paquet 1992), it is plausible that the mule deer's tactics of confrontation would be more effective than the white-tailed deer's use of flight when encountering predators in deep snow. Low-quality food, energetic stress, or disease that impairs an animal's physical condition and ability to respond effectively to predators (Lindström et al. 2003; Quinn and Cresswell 2004; Martin et al. 2006) could lead to annual variation in the shape of vulnerability curves. Fawns might have been more vulnerable to capture in years in which they and-at least in the case of mule deer-the females that protect them were in poorer condition. There can also be variation in the tactics employed by individual animals. The "average" vulnerability of a species can potentially be subdivided to produce a vulnerability curve for individuals that engage in different tactics.

Many biologists have recognized the need to consider heterogeneity introduced by the presence of different age or size classes in the prey population, as well as heterogeneity in the predator population, to increase the realism of predator-prey models (Thompson 1975; Hastings 1983; Werner 1988; Abrams and Walters 1996; Essington and Hansson 2004; Abrams and Quince 2005). We have shown how contrasting forms of prey behavior, without any cor- 
responding difference in size, can lead to characteristic temporal patterns of vulnerability that influence predator foraging behavior and survival patterns for prey. The concept of an age-dependent (or time-dependent) vulnerability function, $v(t)$, provides a quantitative tool that can be used to expand the predator success (prey vulnerability) term commonly included in predator-prey models (Holling 1959; Jeschke and Tollrian 2000; Jeschke 2006).

Our results also supported hypothesis 2, that seasonal variation in vulnerability and hunt activity interact, resulting in different outcomes for seasonal and annual mortality. Not surprisingly, the prey species suffering the highest annual predation rates was the one that was most vulnerable at the time of year when predators devoted the most time to hunting. We introduced seasonal variation in hunt time to our model to reflect shifts in hunt activity that a generalist predator could make in response to seasonal variation in alternative prey (e.g., Miller et al. 2006). Other factors, including the size and behavior of predators (Paquet 1992; Kunkel and Pletscher 1999; Pierce et al. 2000; Downes 2002; Essington and Hansson 2004) and the intrinsic vulnerability of young animals themselves (Kruuk 1972; Patterson et al. 1998), may also lead to seasonal variation in the attention a predator devotes to any particular prey species.

The low rate at which white-tailed deer fawns were encountered in summer, due to the hiding behavior of young fawns, made it difficult for coyotes to eliminate all the fawns in our simulation even when summer hunt time was raised to high levels (fig. $5 a$ ). White-tailed deer fawns fully emerge from hiding about the time that their vulnerability to capture drops. Even though they had a high probability of being encountered during winter (compared with during summer), their low probability of being captured during winter appeared to make them highly resistant to predation after September, even when coyotes devoted considerable time to hunting deer in winter (fig. $5 c$ ). As long as some white-tailed deer fawns survived the summer, there was a good chance that they would be recruited into the population the following spring.

Conversely, the model revealed that cohorts of mule deer fawns were susceptible to annihilation during winter due to the combination of relatively high encounter (compared with during summer) and capture efficiencies (compared with white-tailed deer fawns in the same season). Our model suggested that high levels of winter predation can be sufficient to explain heavy rates of annual predation on mule deer even in years when they suffered low levels of summer predation (fig. $5 c$ ), a conclusion supported by the survival data (fig. 4; 1994, 1999, 2003). Mule deer might escape such high levels of predation in winter by occupying rugged habitats, which enable them to lower the rate at which they are encountered and attacked (Lingle 2002).

An appreciation of the interaction between temporal variation in prey vulnerability and hunt activity should help biologists understand geographic as well as temporal variation in predation rates. For example, if coyotes live in an area with a more profitable food source available in summer but not in winter (e.g., ground squirrels that hibernate), we would expect them to hunt ungulate prey more in winter, which should disadvantage mule deer (compared with mule deer in another region). If coyotes live in an area with a preferred prey species that is readily available in winter (e.g., snowshoe hares [Lepus americanus]), we would expect coyotes to reduce the time spent hunting ungulates in winter, which should benefit mule deer. As with other forms of alternative prey (Patterson et al. 1998; Cooper et al. 1999; Ackerman 2002; Prugh 2005; Miller et al. 2006), the presence of the second deer species would be likely to influence predation on the first (Robinson et al. 2002) and should be considered in future models.

Seasonal variation in vulnerability and mortality raises significant questions for biologists and wildlife managers looking for representative data collection. For instance, if managers were to use fawn : doe ratios obtained from autumn or early winter censuses as an index of fawn recruitment, they could greatly overestimate survival of mule deer fawns, particularly when compared with survival of white-tailed deer fawns. It is important to note that intervals of 3 years were insufficient to reveal the full range of variation in the seasonal pattern or overall levels of mortality. In 1994, 1995, and 1999, fawn mortality was concentrated in winter. From 2000 to 2002, fawn mortality was high during summer. Although an analysis of reasons for this annual variation is beyond the scope of this article, a substantial decline in the abundance of Richardson's ground squirrels (Spermophilus richardsonii) from the mid1990s to 2000 and fluctuations in the availability of cattle (Bos taurus) carcasses appeared to correspond with variation in the timing of predation on deer (Lingle 2000; S. Lingle, unpublished data).

\section{Temporal Variation in Predation Pressure and the Evolution of Prey Defenses}

A few articles have highlighted the importance of temporal variation in predation risk in shaping life-history attributes (Werner 1986; Hairston 1987; Peckarsky et al. 2001), activity patterns, and microhabitat use (Daly et al. 1992; Lima and Bednekoff 1999; Sih and McCarthy 2002). Our results suggest that seasonal variation in predation pressure can be an important selection pressure shaping the contrasting antipredator tactics seen in different species. Ag- 
gressive defense is highly effective in protecting animals that are too young to help themselves (Montgomerie and Weatherhead 1988; Cocroft 2002; Lingle et al. 2005) and may therefore be favored when predation pressure is weighted against younger animals rather than against older animals. Tactics of flight may be favored when predator pressure is weighted toward older animals, who have the physical abilities needed to successfully employ this form of defense.

In addition to factors mentioned above (alternative prey, the type of predator), habitat conditions can interact with prey vulnerability to work against young animals. Although there were few shrubs and no trees at our study site, the density of forbs and grass at this location probably provided better hiding cover for neonatal fawns than many other habitats would. In a more open habitat that enabled predators to increase their encounter rate (e.g., Barrett 1981), an entire cohort of neonatal white-tailed deer fawns could potentially be eliminated because of their high vulnerability to being captured. This may have been the case in 2000 and 2001, drought years in which nearly every white-tailed deer fawn was killed by mid-August. In a habitat that offers poor hiding cover summer after summer, females may have to commit to a strategy of aggressive defense in order for any of their offspring to survive this life stage, even if this strategy is coupled with a constraint on their ability to employ effective tactics of flight in another season. This example illustrates how an appreciation of temporal variation in predation pressure may provide insight into the mule deer's reliance on aggressive tactics and its tendency to occupy more open landscapes than white-tailed deer (Swenson et al. 1983; Wiggers and Beasom 1986).

Although it would be ideal for an animal to be able to employ the ideal response at the appropriate time of year, mechanisms underlying behavior do not always make such perfect responses possible (Caudill and Peckarsky 2003; Sih et al. 2004). Animals may be forced to make tradeoffs in balancing the costs and benefits of managing the risk they face at different times of their lives. On the other hand, it is possible that each of these species is employing the defenses that are optimal in both summer and winter when viewed across their full range of habitats. We need to examine the vulnerability of these and other species at different times of year in a variety of habitats (and with a variety of predators) to determine whether antipredator adaptations developed to manage risk at one time of year constrain an animal's ability to manage its risk an another time of year, or whether these defenses represent the best solution to manage the risk found at each time of year.

An association between social or aggressive defenses and open habitats has been widely reported (Jarman 1974; Lima 1993; Caro et al. 2004). Although such observations provide a valuable starting point, our results suggest that it is insufficient to identify correlations between prey defenses and habitat characteristics to assess the adaptive value of prey defenses. We need to take seasonal variation in prey vulnerability and predation pressure into account before we will understand why certain forms of prey defenses are favored in certain habitats.

\section{Acknowledgments}

We thank the Thrall family and the McIntyre Ranching Company for the privilege of working on their land and B. Cunningham, K. Gallup, H. Heise, M. Pachkowski, L. Schrader, T. Shelton, M. Vachon, and many others for assistance in monitoring fawns and conducting censuses. We are grateful to F. Courchamp, J. Wilmshurst, and two anonymous reviewers for valuable comments on an earlier version of this manuscript and to L. Bartoš and S. Côté for statistical advice. This research was made possible by funding from the Alberta Ingenuity Fund, the Alberta Conservation Association, and the Natural Sciences and Engineering Research Council of Canada.

\section{Literature Cited}

Abrams, P. A., and C. Quince. 2005. The impact of mortality on predator population size and stability in systems with stage-structured prey. Theoretical Population Biology 68:253-266.

Abrams, P. A., and C. J. Walters. 1996. Invulnerable prey and the paradox of enrichment. Ecology 77:1125-1133.

Ackerman, J. T. 2002. Of mice and mallards: positive indirect effects of coexisting prey on waterfowl nest success. Oikos 99:469-480.

Anthony, R. G., and N. S. Smith. 1977. Ecological relationships between mule deer and white-tailed deer in southeastern Arizona. Ecological Monographs 47:255-277.

Barrett, M. W. 1981. Environmental characteristics and functional significance of pronghorn fawn bedding sites in Alberta. Journal of Wildlife Management 45:120-131.

Beasom, S. L., and N. S. Wiggers. 1986. A critical assessment of whitetailed deer and mule deer productivity. Pages 68-79 in P. R. Krausman, ed. Deer in the Southwest: a workshop. University of Arizona, Tuscon.

Bergerud, A. T., H. E. Butler, and D. R. Miller 1984. Antipredator tactics of calving caribou: dispersion in mountains. Canadian Journal of Zoology 62:1566-1575.

Burger, J. 1984. Grebes nesting in gull colonies: protective associations and early warning. American Naturalist 123:327-337.

Caro, T. M., C. M. Graham, C. J. Stoner, and J. K. Vargas. 2004. Adaptive significance of antipredator behaviour in artiodactyls. Animal Behaviour 67:205-228.

Caudill, C. C., and B. L. Peckarsky. 2003. Lack of appropriate behavioral or developmental responses by mayfly larvae to trout predators. Ecology 84:2133-2144.

Cocroft, R. B. 2002. Antipredator defense as a limited resource: unequal predation risk in broods of an insect with maternal care. Behavioral Ecology 13:125-133.

Cooper, S. M., K. E. Holekamp, and L. Smale. 1999. A seasonal feast: 
long-term analysis of feeding behaviour in the spotted hyaena. African Journal of Ecology 37:149-160.

Daly, M., P. R. Behrends, M. I. Wilson, and L. F. Jacobs. 1992. Behavioural modulations of predation risk: moonlight avoidance and crepuscular compensation in a nocturnal desert rodent. Animal Behaviour 44:1-9.

Downes, S. J. 2002. Size-dependent predation by snakes: selective foraging or differential prey vulnerability. Behavioural Ecology 13: 551-560.

Dyrcz, A., J. Witkowski, and J. Okulewicz. 1981. Nesting of "timid" waders in the vicinity of "bold" ones as an antipredator adaptation. Ibis 123:524-554.

Essington, T. E., and S. Hansson. 2004. Predator-dependent functional responses and interaction strengths in a natural food web. Canadian Journal of Fisheries and Aquatic Sciences 61:2215-2226.

Festa-Bianchet, M. 1988. Seasonal range selection in bighorn sheep: conflicts between forage quality, forage quantity, and predator avoidance. Oecologia (Berlin) 75:580-586.

FitzGibbon, C. D. 1990. Anti-predator strategies of immature Thomson's gazelles: hiding and the prone response. Animal Behaviour 40:846-855.

Hairston, N. G., Jr. 1987. Diapause as a predator avoidance adaptation. Pages 281-290 in W. C. Kerfoot and A. Sih, eds. Predation: direct and indirect impacts on aquatic communities. University Press of New England, Hanover.

Hastings, A. 1983. Age-dependent predation is not a simple process. I. Continuous time models. Theoretical Population Biology 23: 347-362.

Haugen, A. O., and D. W. Speake. 1959. Determining age of young fawn white-tailed deer. Journal of Wildlife Management 22:319321.

Holling, C. S. 1959. Some characteristics of simple types of predation and parasitism. Canadian Entomologist 91:385-398.

Hoogland, J. L., K. E. Cannon, L. M. DeBarbieri, and T. G. Manno. 2006. Selective predation on Utah prairie dogs. American Naturalist 168:546-552.

Jarman, P. J. 1974. The social organization of antelope in relation to their ecology. Behaviour 48:215-267.

Jeschke, J. M. 2006. Density-dependent effects of prey defenses and predator offenses. Journal of Theoretical Biology 242:900-907.

Jeschke, J. M., and R. Tollrian. 2000. Density-dependent effects of prey defences. Oecologia (Berlin) 123:391-396.

Krausman, P. R. 1978. Deer-forage relationships in Big Bend National Park, Texas. Journal of Wildlife Management 42:101-107.

Kruuk, H. 1972. The spotted hyena: a study of predation and social behavior. University of Chicago Press, Chicago.

Kunkel, K. E., and D. H. Pletscher. 1999. Species-specific population dynamics of cervids in a multipredator ecosystem. Journal of Wildlife Management 63:1082-1093.

Lima, S. L. 1993. Ecological and evolutionary perspectives on escape from predatory attack: a survey of North American birds. Wilson Bulletin 105:1-47.

Lima, S. L., and P. A. Bednekoff. 1999. Temporal variation in danger drives antipredator behavior: the risk allocation hypothesis. American Naturalist 153:649-659.

Lindström, K. M., I. T. Van de Veen, B. A. Lagault, and J. O. Lindström. 2003. Activity and predator escape performance of common green-finches Carduelis chloris infected with Sindbis virus. Ardea $71: 103-111$

Lingle, S. 2000. Seasonal variation in coyote feeding behaviour and mortality of white-tailed deer and mule deer. Canadian Journal of Zoology 78:85-99.

- 2001. Antipredator strategies and grouping patterns in white-tailed deer and mule deer. Ethology 107:295-314.

. 2002. Coyote predation and habitat segregation of whitetailed deer and mule deer. Ecology 83:2037-2048.

- 2003. Group composition and cohesion in sympatric whitetailed deer and mule deer. Canadian Journal of Zoology 81:11191130.

Lingle, S., and S. M. Pellis. 2002. Fight or flight? antipredator behavior and escalation of coyote encounters with deer. Oecologia (Berlin) 131:154-164.

Lingle, S., S. M. Pellis, and W. F. Wilson. 2005. Interspecific variation in antipredator behaviour leads to differential vulnerability of mule deer and white-tailed deer fawns to coyote predation early in life. Journal of Animal Ecology 74:1140-1149.

Lloyd, M., and H. S. Dybas. 1966. The periodical cicada problem. I. Population ecology. Evolution 20:133-149.

Mackie, R. J. 1964. Montana deer weights. Montana Wildlife 4:914.

Martin, J., L. de Neve, V. Polo, J. A. Fargallo, and M. Soler. 2006. Health-dependent vulnerability to predation affects escape responses of unguarded chinstrap penguin chicks. Behavioral Ecology and Sociobiology 60:778-784.

Messier, F., and C. Barrette. 1985. The efficiency of yarding behaviour by white-tailed deer as an antipredator strategy. Canadian Journal of Zoology 63:785-789.

Miller, D. A., J. B. Grand, T. F. Fondell, and M. Anthony. 2006. Predator functional response and prey survival: direct and indirect interactions affecting a marked prey population. Journal of Animal Ecology 75:101-110.

Molinari-Jobin, A., P. Molinari, A. Loison, J.-M. Gaillard, and U. Breitenmoser. 2004. Life cycle period and activity of prey influence their susceptibility to predators. Ecography 27:323-329.

Montgomerie, R. D., and P. J. Weatherhead. 1988. Risks and rewards of nest defence by parent birds. Quarterly Review of Biology 63: 167-187.

Nicholson, M. C., R. T. Bowyer, and J. G. Kie. 1997. Habitat selection and survival of mule deer: tradeoffs associated with migration. Journal of Mammalogy 78:483-504.

Paquet, P. C. 1992. Prey use strategies of sympatric wolves and coyotes in Riding Mountain National Park, Manitoba. Journal of Mammalogy 73:337-343.

Patterson, B. R., L. K. Benjamin, and F. Messier. 1998. Prey switching and feeding habits of eastern coyotes in relation to snowshoe hare and white-tailed deer densities. Canadian Journal of Zoology 76: 1885-1897.

Peckarsky, B. L., B. W. Taylor, A. R. McIntosh, M. A. McPeek, and D. A. Lytle. 2001. Variation in mayfly size at metamorphosis as a developmental response to risk of predation. Ecology 82:740-757.

Pierce, B. M., V. C. Bleich, and R. T. Bowyer. 2000. Selection of mule deer by mountain lions and coyotes: effects of hunting style, body size, and reproductive status. Journal of Mammalogy 81:462-472.

Prugh, L. R. 2005. Coyote prey selection and community stability during a decline in food supply. Oikos 110:253-264.

Quinn, J. L., and W. Cresswell. 2004. Predator hunting behaviour and prey vulnerability. Journal of Animal Ecology 72:143-154.

Ralls, K., K. Kranz, and B. Lundrigan. 1986. Mother-young relationships in captive ungulates: variability and clustering. Animal Behaviour 34:134-145. 
Robinson, H. S., R. B. Wielgus, and J. C. Gwilliam. 2002. Cougar predation and population growth of sympatric mule deer and white-tailed deer. Canadian Journal of Zoology 80:556-568.

Seber, G. A. F. 2002. The estimation of animal abundance and related parameters. 2nd ed. Blackwell, Caldwell, NJ.

Sih, A., and T. M. McCarthy. 2002. Prey responses to pulses of risk and safety: testing the risk allocation hypothesis. Animal Behaviour 63:437-443.

Sih, A., A. Bell, and J. C. Johnson. 2004. Behavioral syndromes: an ecological and evolutionary overview. Trends in Ecology \& Evolution 19:372-378.

Swenson, J. E., S. J. Knapp, and H. J. Wentland. 1983. Winter distribution and habitat use by mule deer and white-tailed deer in southeastern Montana. Prairie Naturalist 15:97-113.

Thompson, D. J. 1975. Towards a predator-prey model incorporating age structure: the effect of predator and prey size on the predation of Daphnia magna by Ischnura elegans. Journal of Animal Ecology 44:907-916.
Werner, E. E. 1986. Amphibian metamorphosis: growth rate, predation risk, and the optimal size at transformation. American Naturalist 128:319-341.

1988. Size, scaling and the evolution of complex life cycles. Pages 60-81 in L. Persson and B. Ebenmann, eds. Size-structured populations: ecology and evolution. Springer, New York.

Whittaker, D. G., and F. G. Lindzey. 1999. Effect of coyote predation on early fawn survival in sympatric deer species. Wildlife Society Bulletin 27:256-262.

- 2001. Population characteristics of sympatric mule and white-tailed deer on Rocky Mountain Arsenal, Colorado. Journal of Wildlife Management 65:946-952.

Wiggers, E. P., and S. L. Beasom. 1986. Characterization of sympatric or adjacent habitats of 2 deer species in west Texas. Journal of Wildlife Management 50:129-134.

Associate Editor: Tim Coulson Editor: Donald L. DeAngelis 